\title{
Cancer Immunotherapy and the Immune Response in Follicular Lymphoma
}

\author{
Frank Stenner ${ }^{1 *}$ and Christoph Renner ${ }^{2}$ \\ ${ }^{1}$ Department of Oncology, University Hospital Basel, Basel, Switzerland, ${ }^{2}$ Department of Biomedicine, University of Basel, \\ Basel, Switzerland
}

Follicular lymphoma (FL) is the most frequent indolent lymphoma in the Western world and is characterized in almost all cases by the $t(14 ; 18)$ translocation that results in overexpression of BCL2, an anti-apoptotic protein. The entity includes a spectrum of subentities that differ from an indolent to a very aggressive growth pattern. As a consequence, treatment can include watch \& wait up to intensive chemotherapy including allogeneic stem cell transplantation. The immune cell microenvironment has been recognized as a major driver of outcome of FL patients and gene expression profiling has identified a clinically relevant gene expression signature that classifies an immune response to the lymphoma cells. It is known for some time that the immune cell composition of the

OPEN ACCESS

Edited by:

Andrés José María Ferreri, San Raffaele Scientific Institute

(IRCCS), Italy

Reviewed by: Alessandro Poggi,

Ospedale Policlinico San

Martino, Italy

Stefano Luminari,

Università degli Studi di Modena e

Reggio Emilia, Italy

*Correspondence:

Frank Stenner

frank.stenner@usb.ch

Specialty section: This article was submitted to

Cancer Immunity and Immunotherapy,

a section of the journal

Frontiers in Oncology

Received: 21 March 2018

Accepted: 29 May 2018

Published: 19 June 2018

Citation:

Stenner F and Renner C (2018)

Cancer Immunotherapy and the Immune Response in

Follicular Lymphoma.

Front. Oncol. 8:219.

doi: 10.3389/fonc.2018.00219 lymphoma microenvironment is important because high numbers of tissue-infiltrating macrophages correlate with poor outcome in patients receiving chemotherapy but not in patients receiving the combination of chemotherapy and CD20-specific monoclonal antibody rituximab. In addition, TCR signaling of tumor-infiltrating lymphocytes is dysfunctional leading to an impaired capacity to form an intact immunologic synapse. Approaches restoring local $T$ cell function, e.g., by usage of checkpoint inhibitors has demonstrated clinical activity (ORR 40\%) and can achieve long-term remissions. Ongoing trials with re-programmed autologous CART cells achieve response rates in approximately $50 \%$ of FL patients with relapsed and even refractory disease. Responses lasting for more than 6 months might be durable, indicative for a successful restoration of a functional immune system. In summary, FL is a malignant disease where the control by the immune system ultimately decides about progression and transformation rate. The advent of monoclonal antibodies has changed the way we treat $F L$ and new approaches restoring the individual immune control will hopefully improve results further.

Keywords: follicular lymphoma, indolent lymphoma, monoclonal antibodies, bispecific antibodies, radioimmunotherapy, checkpoint blockade inhibitors, chimeric antigen receptor therapy

\section{INTRODUCTION}

The aim of this review is to present the current therapeutic landscape of follicular lymphoma (FL) and to discuss early results of immunotherapies, e.g., checkpoint inhibitors and CAR T-cell therapies in the context of the immune system.

The clinically established therapeutic options for FL today are mainly focused on cytoreduction. Without the exception of the CD20 targeted therapies the recruitment of the patient's immune

Abbreviations: CR, complete response; PR, partial response; PD, progressive disease; FL, follicular lymphoma; OS, overall survival; CART, chimeric antigen receptor therapy. 
system is not actively utilized in the conventional therapy of FL. However, for long-term benefits, it will be crucial to make progress in that direction, otherwise FL will continue to be an incurable and chronic disease. Thus, understanding the interplay between FL cells and their environment will be key for further success in this disease.

Other than in aggressive B-cell lymphomas like diffuse large B-cell lymphoma (DLBCL), the principle structure of the lymph node is more conserved in FL. In FL, the lymph node architecture is not destroyed, and the nodes boundaries are better respected by the tumor. The longevity of the malign B-cell, more than the aggressive behavior of these cells leads to abnormal large follicles. This phenotype is a result of the increase of lymphocyte numbers in the germinal centers that swell due to the sheer load. In FL, the often slow progression also leads into a long-standing relationship of the increasing B-cell numbers and their neighboring immune cells and the stromal microenvironment. This results inevitably in shifts and alterations within the immune microcosm. T-cells in FL lesions have been found to be increased (Zhang/Ansell); however, these T-cells, when examined in detail, often display features of T-cell exhaustion, for example, high expression of PD-1 or TIM-3 (1). Putative tumor supporting T-cells from T-cell subsets especially T-helper cells, T-cells (Tregs), and there most prominently follicular regulatory T-helper cells (FOXP3+) become involved in the protection of the malignant FL clone and foster its immune evasion.

The importance of an effective T-cell surveillance in the context of lymphoma has been demonstrated in various mouse models. For example, immunodeficient mice that lack T-cell or NK cell effector molecules like perforin or IFN- $\gamma$ develop spontaneous lymphomas. These lymphomas when transferred on wild-type littermates are immediately rejected by CD8 positive T-cells $(2,3)$. In summary, suppression of a T-cell-mediated antitumor response appears to be instrumental for the initial establishment and further development of FL.

With a remarkable variability of clinical courses in FL, several efforts to better predict outcome according to biological features of the individual disease have been made. A gene expressionbased model has identified two subsets of immune signatures in FL with distinct biologic attributes in FL that are associated with survival (4). These specific signatures were not expressed in the malign or benign B-cells but the genes in the immune response 1 signature were more highly expressed in T cells than in any of the B-cell or monocyte subpopulations, and genes of immune response 2 were more pronounced expressed in both $\mathrm{T}$ cells and monocytes but not in B-cells. Patients with immune signature 1 had a better outcome than those of immune signature 2, underscoring an important contribution of monocytes for a more dismal outcome in FL.

The role of monocytes in FL was further substantiated by a study (5) that found upregulated CCR1 and CD68-positive immune cells within FL lesions indicating a monocytes and macrophages recruitment. This pattern was apparently associated with worse survival in FL. In contrary, higher numbers of T-cells with elevated levels of CD3 and the early T-cell antigen CD7 were correlated with better survival in the examined cohort. Finally, CD4 and CD8 subsets were not significantly associated with outcome. Both findings are in line with the observation of two distinct immune profiles published by Dave et al. (4). These results confirm the role of the host immune responses for the outcome in FL and specifically demonstrate that the degree of infiltrating CD68 macrophages and CD7-positive T-cells is prognostically useful, together with identification of CCR 1 as a putative novel prognostic indicator and a marker for an immune switch between macrophage and T cell-dominant response. With the advent of immune targeted therapies either against tumor supporting T-cells of lymphoma-associated macrophages, the vision of a chemotherapy free regimen for FL comes closer to reality.

\section{BIOLOGY OF FL}

Follicular lymphoma is among the most frequently occurring entities of indolent non-Hodgkin's lymphoma. Generally, FL presents as a slowly growing disease, which can be quite asymptomatic for some time. Once clinical problems are noted it is rather by compression of other structures than invasion or destruction of adjacent structures. If FL is detected in early stages (I and II) radiotherapy has curative potential. However, due to frequent bone marrow involvement (stage IV), many patients are not eligible for this curative option. Ultimately, almost all patients will experience relapse, and a proportion of patients will develop an aggressive disease with high risk of transformation. The annual rate of histological transformation in FL patients is estimated with 3\% (6). Although advanced FL is considered incurable, recent advances in the treatment and management of this disease have made a significant impact on progression-free survival (PFS) and patient quality of life. Long treatment-free survival intervals in some patients suggest a possible cure in a subset of these patients, but as of today it is too early to make this claim. Even if FL is still considered incurable, affected patients generally have a long median overall survival (OS) that can reach 10 years or more. The advent of monoclonal antibody therapy in conjunction with new chemotherapeutics and the addition of radionuclides in the recent past have had a significant impact on FL management and have resulted in much better outcomes.

\section{CLINICAL PRESENTATION AND COURSE OF FL}

Most patients initially present with asymptomatic peripheral lymphadenopathy, affecting the cervical, axillary, femoral, and inguinal regions (7). Although lymph nodes are most commonly involved, the disease may also originate at or affect certain extranodal sites. These include the duodenum, skin, thyroid, salivary gland, and the breast (8). Stage IV disease is present in approximately two-third of the cases most often demonstrated by involvement of the bone marrow (9). Clinical features like night sweats and weight loss-typically associated with more aggressive forms of lymphomas such as DLBCL—might be present but are often missing even in higher stages of the disease. The ESMO recommendations appreciate the diversity of the FL subtypes, and the therapeutic options for the individual patients should be taken into consideration when planning the appropriate therapy (10). 


\section{IMMUNOCHEMOTHERAPY AND RADIOTHERAPY FOR FL}

Passive immunotherapy, e.g., monoclonal antibodies against $\mathrm{CD} 20$, in combination with a chemotherapy backbone is currently the standard of care for patients with advanced-stage FL in need of treatment (10-13). Some patients with a low burden may be treated with CD20-specific antibodies (such as rituximab) only. However, a proportion of patients do not respond to standard treatment, and the majority will relapse after an initial response, highlighting the need for other more effective and durable therapies. An alternative approach to monoclonal antibodies with or without chemotherapy is the usage of radionuclide labeled anti-CD20 antibodies that are described in more details later in the article.

Radiotherapy has a potential to improve PFS and improves OS for FL patients with early clinical stages (I and II) by approximately $15 \%(14,15)$. The standard radiation dose for FL is $24 \mathrm{~Gy}$ and has been shown to be superior to 4 Gy delivered as $2 \times 2$ (FORT trial) (16). However, long-term remissions in advanced FL patients receiving TBI with $2 \mathrm{~Gy} \times 2$ Gy and patients who had aborted the full doses for various reasons have been observed. Therefore, given the exquisite radiosensitivity of FL and the presumable added control by the immune system when applying lower doses of radiation suggest that there is a mechanism of radiotherapy beyond sheer lymphoma cell destruction.

\section{Identification and Characterization of Potential Target Antigens}

Being a more mature B-cell disorder, FL displays the immunophenotype of follicular center B-cells. Pan-B-cell markers (CD19, CD20, CD22, and IgM) are present with a co-expression of CD10. In contrast to reactive B-cells, FL cells express BCL2. The expression of this anti-apoptotic protein due to $t(14 ; 18)$ (q32;q21) event, that brings the BCL-2 gene under the activity of the Ig heavy chain promoter is regarded to be pathognomonic for the disease. For therapeutic purposes, CD20 followed by CD19, CD22, and CD74 appear to be valid targets for immunotherapy $(17,18)$. While CD20 is a non-internalizing antigen, the latter three are internalized and they have or will be tested in trials utilizing antibody drug conjugates that rely on internalization (Table 1 includes various contemporary approaches in FL).

\section{Development of Monoclonal CD20-, CD19-, and CD22-Specific Antibodies}

Rituximab has been the first monoclonal antibody entering clinical practice in a variety of lymphomas of the B-cell origin. Thus, it was no surprise that rituximab has found an undisputed place in the treatment of FL. Other than in aggressive lymphomas, strategies using monotherapy of rituximab with and without maintenance have been established successfully (19-21). Consequently, guidelines like ESMO recommend to start rituximab in patients in need of therapy but with low tumor burden and slow progression (10). With the advent of type II monoclonal antibodies, namely, obinutuzumab the landscape of treatment begins to shift. Obinutuzumab is a glycoengineered, afucosylated anti-CD20 antibody with increased antibody-dependent cellular cytotoxicity and increased antitumor activity by FC $\gamma$ RIII compared with rituximab or ofatumamab (22). In a phase III trial (GALLIUM), patients were randomized 1:1 to receive either obinutuzumab and chemotherapy or rituximab and chemotherapy, followed in responding patients by obinutuzumab or rituximab maintenance for up to 2 years. There, an advantage of obinutuzumab regarding PFS compared with rituximab was shown (23). In 2017, the Food and Drug Administration approved obinutuzumab (GAZYVA, Genentech, Inc.) in combination with chemotherapy, followed by obinutuzumab monotherapy in patients achieving at least a partial remission, for the treatment of adult patients with previously untreated stage II bulky, III, or IV FL, respectively.

\section{Antibody-Based Radio-Immunotherapy}

Bexxar (131I-tositumomab) and zevalin (90Y-ibritumomab tiuxetan) have been approved in the US and zevalin also in Europe. Both agents can achieve meaningful responses, as shown by an approximately $75 \%$ complete response (CR) rate in patients treated with 131I-tositumomab (24). In some cases, these responses lead to long-lasting remissions. Widespread use of these therapies has been hampered by challenging logistics and the restricted availability outside specialized centers. Thus, among the growing list of therapeutic options for FL, the radioimmunotherapeutics lead a shadowy existence.

\section{Antibody-Based Immunotoxins (ITs)}

SGN-CD19B, a PBD conjugated antibody, has shown its best preclinical responses in FL when compared with other B-cell malignancies (25). ITs have the advantage of increased efficacy by reduced toxicity compared with antibody chemotherapy combinations. Whether long-term control of FL like in some patients treated with rituximab monotherapy seen in SAKK 35/98 trial (26) is achievable with antibody-based ITs also has to be seen in future.

\section{HIGH DOSE CHEMOTHERAPY FOLLOWED BY AUTOLOGOUS OR ALLOGENIC STEM CELL TRANSPLANTATION}

Transplant concepts found their place in the pre-rituximab era, when relapses were more frequent and swift than after the introduction of the CD20 antibody. Beside recognition of its curative potential transplantation lost ground in the therapeutic algorithm of FL with the introduction of rituximab. Today, it can be regarded consensus to use high-dose chemotherapy followed by autologous stem cell transplantation (HDCT/ASCT) as a salvage treatment. In patients with refractoriness to first-line treatment and transformed lymphomas, this concept should be applied earlier. Allogenic stem cell transplantation has curative potential but carries a mortality risk for patients with FL (16). The benefit of a total reset of the immune system and a graft versus lymphoma effect are undeniable, but the risk involved for the patient is significant. Therefore, a careful upfront risk benefit evaluation should be done. Allogeneic transplantation should be reserved for patients failing of HDCT/ASCT [for an excellent review on 
TABLE 1 | Ongoing trials in follicular lymphoma (FL) with immune interventions on clinical.trials.gov.

\begin{tabular}{|c|c|c|c|c|}
\hline Spalte1 & Study & Condition & Study drug & NCT-ID \\
\hline 1 & $\begin{array}{l}\text { Sequential intranodal immunotherapy (SIIT) combined } \\
\text { with anti-PD1 (pembrolizumab) in follicular lymphoma }\end{array}$ & $\mathrm{Fl}$ and other $\mathrm{NHL}$ & Pembrolizumab & NCT02677155 \\
\hline 2 & $\begin{array}{l}\text { Active specific immunotherapy for follicular lymphomas with } \\
\text { tumor-derived immunoglobulin idiotype antigen vaccines }\end{array}$ & $\mathrm{Fl}$ and other $\mathrm{NHL}$ & Id-KLH vaccine|GM-CSF & NCT00001512 \\
\hline 3 & $\begin{array}{l}\text { Cellular adoptive immunotherapy in treating patients with } \\
\text { relapsed or refractory follicular non-Hodgkin's lymphoma }\end{array}$ & $\mathrm{Fl}$ and other $\mathrm{NHL}$ & Aldesleukin plus rituximab & NCT00182650 \\
\hline 4 & $\begin{array}{l}\text { Bl } 695500 \text { vs rituxan first line treatment in patients with } \\
\text { low tumor burden follicular lymphoma }\end{array}$ & $\mathrm{Fl}$ and other $\mathrm{NHL}$ & Rituximab|BI 695500 & NCT02417129 \\
\hline 5 & $\begin{array}{l}\text { Monoclonal antibody CT-011 in combination with rituximab } \\
\text { in patients with relapsed follicular lymphoma }\end{array}$ & $\mathrm{Fl}$ and other $\mathrm{NHL}$ & CT-011|rituximab & NCT00904722 \\
\hline 6 & $\begin{array}{l}\text { Rituximab with or without yttrium Y-90 ibritumomab tiuxetan } \\
\text { in treating patients with untreated follicular lymphoma }\end{array}$ & Follicular lymphoma & $\begin{array}{l}\text { Rituximab|radiation: yttrium Y-90 ibritumomab } \\
\text { tiuxetan }\end{array}$ & NCT02320292 \\
\hline 7 & $\begin{array}{l}\text { Vaccine therapy plus interleukin-2 in treating patients with } \\
\text { stage III, stage IV, or recurrent follicular lymphoma }\end{array}$ & $\mathrm{Fl}$ and other $\mathrm{NHL}$ & Aldesleukin|autologous tumor cell vaccine & NCT00020462 \\
\hline 8 & Zevalin. First line in follicular lymphoma & Follicular lymphoma & $\begin{array}{l}\text { 90Yttrium-ibritumomab tiuxetan + rituximab; } \\
\text { rituximab }\end{array}$ & NCT00772655 \\
\hline 15 & $\begin{array}{l}\text { Phase I dose escalation study of IMMU-114 (anti-HLA DR) } \\
\text { in relapsed or refractory NHL and CLL }\end{array}$ & $\mathrm{Fl}$ and other $\mathrm{NHL}$ & IMMU-114 & NCT01728207 \\
\hline 16 & $\begin{array}{l}\text { Agatolimod (anti-toll } 9 \text { receptor), rituximab, and yttrium } \\
\text { Y } 90 \text { ibritumomab tiuxetan }\end{array}$ & $\mathrm{Fl}$ and other $\mathrm{NHL}$ & $\begin{array}{l}\text { Agatolimod sodium|radiation: indium } \ln -111 \\
\text { ibritumomab tiuxetan }\end{array}$ & NCT00438880 \\
\hline 17 & $\begin{array}{l}\text { Radiolabeled monoclonal antibody plus rituximab with and } \\
\text { without filgrastim and interleukin-11 }\end{array}$ & $\mathrm{Fl}$ and other $\mathrm{NHL}$ & Rituximab|yttrium Y 90 ibritumomab tiuxetan & NCT00012298 \\
\hline 19 & $\begin{array}{l}\text { Epratuzumab (anti-CD22) in treating patients with } \\
\text { non-Hodgkin's lymphoma }\end{array}$ & $\mathrm{Fl}$ and other $\mathrm{NHL}$ & Epratuzumab & NCT00022685 \\
\hline 20 & $\begin{array}{l}\text { Denintuzumab mafodotin (SGN-CD19A) combined } \\
\text { with RCHOP or RCHP versus RCHOP alone }\end{array}$ & $\mathrm{Fl}$ and other $\mathrm{NHL}$ & $\begin{array}{l}\text { Denintuzumab } \\
\text { mafodotin|rituximab|chemotherapy }\end{array}$ & NCT02855359 \\
\hline 21 & $\begin{array}{l}\text { Study evaluating the efficacy and safety of PCAR-019 in } \\
\text { CD19 positive relapsed or refractory leukemia and lymphoma }\end{array}$ & $\mathrm{Fl}$ and other $\mathrm{NHL}$ & PCAR-019 (anti-CD19 CAR-T cells) & NCT02851589 \\
\hline 23 & $\begin{array}{l}\text { Treatment study of denintuzumab mafodotin (SGN-CD19A) } \\
\text { plus RICE versus RICE alone for diffuse large B-cell lymphoma }\end{array}$ & $\mathrm{Fl}$ and other $\mathrm{NHL}$ & $\begin{array}{l}\text { Denintuzumab } \\
\text { mafodotin|rituximab|chemotherapy }\end{array}$ & NCT02592876 \\
\hline 24 & $\begin{array}{l}\text { Immunotherapy with ex vivo-expanded cord blood-derived } \\
\text { NK cells combined with rituximab HDCT/ASCT for B-NHL }\end{array}$ & $\mathrm{Fl}$ and other $\mathrm{NHL}$ & NK cells|rituximab|chemotherapy|ASCT & NCT03019640 \\
\hline 25 & Idiotype vaccine for low-grade non-Hodgkin's lymphoma & $\mathrm{Fl}$ and other $\mathrm{NHL}$ & Favld (Id-KLH) active immunotherapy & NCT00036426 \\
\hline 26 & $\begin{array}{l}\text { Rituxan plus favid (idiotype vaccine) for low-grade } \\
\text { non-Hodgkin's lymphoma }\end{array}$ & $\mathrm{Fl}$ and other $\mathrm{NHL}$ & $\mathrm{Id}-\mathrm{KLH}$ & NCT00041730 \\
\hline
\end{tabular}

An overview of trials in FL that are currently examining the role of conventional, e.g., non-cellular interventions (antibodies, vaccines, etc.).

this topic, see Ref. (27)]. In future, allogenic transplant will be seriously challenged by less toxic chimeric T-cell approaches described below.

\section{CHECKPOINT BLOCKADE INHIBITING ANTIBODIES}

Like in other lymphomas, PD-1-blocking antibodies have been in FL tried with varying success. To summarize the attempts from the data available at this time, we start with the curious story of pidilizumab. Pidilizumab was developed by CureTech and was later acquired by Pfizer. For the longest time, it was thought that pidilizumab is a PD-1 targeting antibody and the initial clinical trials showed efficacy and tolerablity compatible with a typical PD-1 antibody profile. In a phase II trial, pidilizumab revealed promising activity in FL. From 29 enrolled patients, 19 had an objective response with a CR in $15 / 29$ (52\%) and a partial response (PR) in 4/29 patients (14\%) (28).

However, when it came to FDA filing for approval, it was found that the binding of pidilizumab was unclear, and the company had to invest further research to clarify the target. Meanwhile, DLL1 has been identified as the genuine target, and it remains to be seen how this anti-DLL1 antibody will integrate into the treatment landscape of FL.

In a pivotal basket trial of relapsed/refractory non-Hodgkin lymphomas, patients were treated with single-agent nivolumab (29). Here, FL showed the highest objective response rates (40\%) followed by DLBCL (36\%). Interestingly, in the translational part of the study, the malignant FL cells were mostly negative for PD-L1 and PD-L2. These two antigens, considerably the therapeutic targets, were often expressed on bystander cells in 
the microenvironment. This fact demands further basic studies to elucidate the mechanism behind checkpoint inhibition in FL.

Regarding checkpoint blockade, it can be expected that a combinational approach of passive immunotherapy (anti-CD20) with anti-PD1 antibodies has potential. At the ASH meeting 2017, first data from a trial combining rituximab with pembrolizumab were shown (30). Here, 30 patients with relapsed FL received rituximab plus pembrolizumab for a total of 16 infusions. With a median observation time of 14 months, no death was noted. The ORR was $67 \%$ with a CR rate of $50 \%$. This compares favorably to historical response rates of rituximab of $40 \%$. Currently, a single arm study (NCT03245021) is recruiting and will explore the role of nivolumab in combination with rituximab in first-line therapy of FL. It has to be mentioned the true value of nivolumab may not be determined without a comparator arm of rituximab monotherapy. In the near future, a variety of immunotherapy combination trials will be completed, and it is very likely that the inclusion of checkpoint blockade into standard therapy of FL will improve the outcome of affected patients (for an overview of ongoing trials evaluating novel therapies from 3 to 6 , see Table 1).

\section{CHIMERIC ANTIGEN RECEPTOR THERAPY (CART)}

Data regarding CAR therapy in patients with FL is sparse. Especially, early disease and low-grade FL have not been addressed by clinical trials yet. The CAR $\mathrm{T}$ cell products relevant to FL treatment are CD19 re-targeted T-cells. These products include axicabtagene ciloleucel/Yescarta ${ }^{\circledR}$ and Tisagenleleucel/ $\mathrm{Kymriah}^{\circledR}$ that are FDA approved. The best available information for CAR therapy in FL we have at this moment is from patients participating in the Juliet trial. At ASH 2015, Schuster presented the outcome of $14 \mathrm{FL}$ patients with an ORR of $73 \%$ at 3 months with 4 CRs, 4 PRs, and 3 progressive disease. Three of the four PR patients converted into CRs by 6 months and the last patient with $\mathrm{PR}$ remained in $\mathrm{PR}$ for a year before progression of the disease (31). In an updated analysis encompassing 24 patients, an ORR of $53 \%$ was published. At a median follow-up of 28.6 months, sustained remissions were observed and $89 \%$ of patients with FL who had an initial response (95\% CI, 43-98) could maintain the response (20).

The most notable side effects of CART therapies are cytokine release syndromes found across trials in 50-60\%, up to $10 \%$ severe (grade 4) and neurological toxicities that appear in frequencies from 25 to $30 \%$ and are severe ( $\geq$ grade 4 ) in approximately $5 \%$. Neurotoxicity seemed to be associated with the CAR construct itself, as JCAR015 showed higher toxicities than other constructs. In a post hoc analysis of the Rocket 1 , trial factors associated with higher neurotoxicity were the conditioning chemotherapy (Flu/ CY or not) with a higher risk odds ratio of 7.23, the bridging chemotherapy (OR 4,68), age below 30 (OR 5.16), and less or equal 2 previous line of therapies (OR 7.24) (21). No association with higher risk was found regarding prior CNS irradiation, prior IT chemotherapy, prior CNS disease, prior allogeneic

TABLE 2 | Ongoing trials chimeric antigen receptor therapy (CART) trials including follicular lymphoma (FL) on clinical.trials.gov.

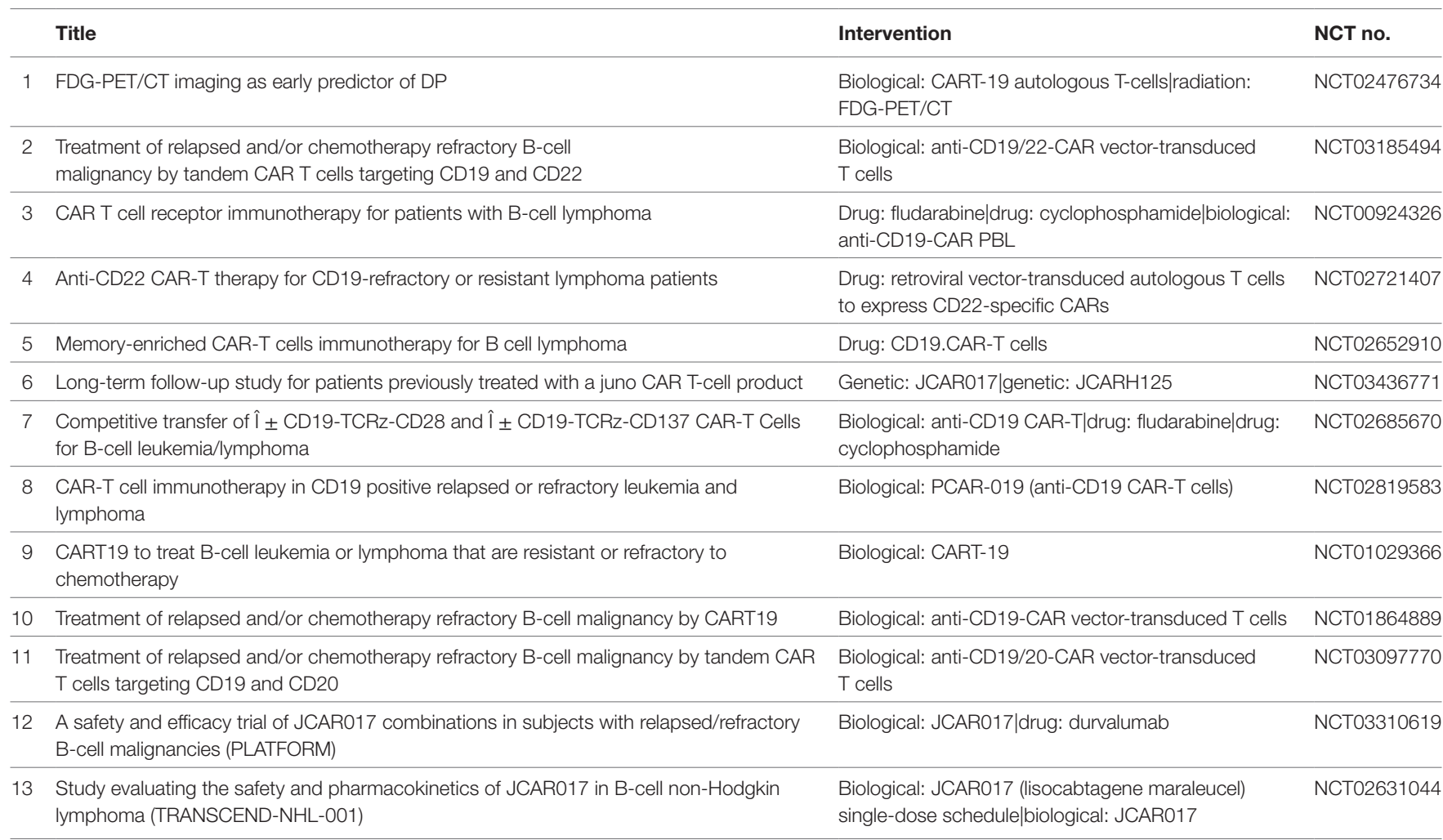

An overview of the contemporary CART trials that include FL patients, with the experimental intervention and the trial accession number in the second and third row. 
transplantation, higher ECOG performance status, or prior use of blinatumumab (21).

With the approval of two CART products in relapsed/refractory aggressive B-cell lymphomas and some 13 trials ongoing (Table 2), the value of the CART approach in FL should become clearer in the next couple of years. If long-lasting remissions can be achieved, this approach has the potential to displace autologous and allogenic stem cell transplantation in FL.

\section{SUMMARY AND OUTLOOK}

Follicular lymphoma represents in the most instances an indolent disease and tolerance of the malignant clone by the immune system is very likely. The mutational load that predicts for immune responses appears not to be exceedingly high in this disease. It is quite likely that immunotherapy with checkpoint blockade inhibitors may not find a place in the early course

\section{REFERENCES}

1. Yang Z-Z, Grote DM, Ziesmer SC, Niki T, Hirashima M, Novak AJ, et al. IL-12 upregulates TIM-3 expression and induces $\mathrm{T}$ cell exhaustion in patients with follicular B cell non-Hodgkin lymphoma. J Clin Invest (2012) 122:1271-82. doi:10.1172/JCI59806

2. Street SE, Trapani JA, MacGregor D, Smyth MJ. Suppression of lymphoma and epithelial malignancies effected by interferon gamma. J Exp Med (2002) 196:129-34. doi:10.1084/jem.20020063

3. Smyth MJ, Thia KY, Street SE, MacGregor D, Godfrey DI, Trapani JA. Perforinmediated cytotoxicity is critical for surveillance of spontaneous lymphoma. J Exp Med (2000) 192:755-60. doi:10.1084/jem.192.5.755

4. Dave SS, Wright G, Tan B, Rosenwald A, Gascoyne RD, Chan WC, et al. Prediction of survival in follicular lymphoma based on molecular features of tumor-infiltrating immune cells. N Engl J Med (2004) 351:2159-69. doi:10.1056/NEJMoa041869

5. Byers RJ, Sakhinia E, Joseph P, Glennie C, Hoyland JA, Menasce LP, et al. Clinical quantitation of immune signature in follicular lymphoma by RT-PCRbased gene expression profiling. Blood (2008) 111:4764-70. doi:10.1182/ blood-2007-10-115915

6. Link BK, Maurer MJ, Nowakowski GS, Ansell SM, Macon WR, Syrbu SI, et al. Rates and outcomes of follicular lymphoma transformation in the immunochemotherapy era: a report from the university of Iowa/Mayo clinic specialized program of research excellence molecular epidemiology resource. J Clin Oncol (2013) 31:3272-8. doi:10.1200/JCO.2012.48.3990

7. Luminari S, Bellei M, Biasoli I, Federico M. Follicular lymphoma-treatment and prognostic factors. Rev Bras Hematol Hemoter (2012) 34:54-9. doi:10.5581/1516-8484.20120015

8. Takata K, Miyata-Takata T, Sato Y, Yoshino T. Pathology of follicular lymphoma. J Clin Exp Hematop (2014) 54:3-9. doi:10.3960/jslrt.54.3

9. Salles GA. Clinical features, prognosis and treatment of follicular lymphoma. Hematology Am Soc Hematol Educ Program (2007) 2007:216-25. doi:10.1182/ asheducation-2007.1.216

10. Dreyling M, Ghielmini M, Rule S, Salles G, Vitolo U, Ladetto M, et al. Newly diagnosed and relapsed follicular lymphoma: ESMO clinical practice guidelines for diagnosis, treatment and follow-up. Ann Oncol (2017) 28:3109. doi:10.1093/annonc/mdx020

11. Rummel MJ, Niederle N, Maschmeyer G, Banat GA, von Grünhagen U, Losem $\mathrm{C}$, et al. Bendamustine plus rituximab versus $\mathrm{CHOP}$ plus rituximab as first-line treatment for patients with indolent and mantle-cell lymphomas: an open-label, multicentre, randomised, phase 3 non-inferiority trial. Lancet (2013) 381:1203-10. doi:10.1016/S0140-6736(12)61763-2

12. Salles G, Seymour JF, Offner F, López-Guillermo A, Belada D, Xerri L, et al. Rituximab maintenance for 2 years in patients with high tumour burden follicular lymphoma responding to rituximab plus chemotherapy (PRIMA): of the disease. However, more aggressive variants, e.g., grade IIIA and higher of FL may represent better targets and should be explored in this regard. Furthermore, during the often long course of the disease, it is reasonable to assume that the malignant clone acquires additional genomic alterations that could make it more prone to respond to checkpoint blockade inhibitors. Finally, FL that transforms into higher grade B-cell lymphoma has a poorer prognosis than de novo high-grade B-cell lymphomas. There, a space for immunotherapy on its own or as an adjunct to a standard therapy could be envisioned. However, with a good variety of therapeutic options at hand the role of immunotherapy in the landscape of treating FL has still to be established.

\section{AUTHOR CONTRIBUTIONS}

CR and FS contributed equally.

a phase 3, randomised controlled trial. Lancet (2011) 377:42-51. doi:10.1016/ S0140-6736(10)62175-7

13. Luminari S, Ferrari A, Manni M, Dondi A, Chiarenza A, Merli F, et al. Long-term results of the FOLL05 trial comparing R-CVP versus R-CHOP versus R-FM for the initial treatment of patients with advanced-stage symptomatic follicular lymphoma. J Clin Oncol (2018) 36:689-96. doi:10.1200/ JCO.2017.74.1652

14. Vargo JA, Gill BS, Balasubramani GK, Beriwal S. What is the optimal management of early-stage low-grade follicular lymphoma in the modern era? Cancer (2015) 121:3325-34. doi:10.1002/cncr.29491

15. Pugh TJ, Ballonoff A, Newman F, Rabinovitch R. Improved survival in patients with early stage low-grade follicular lymphoma treated with radiation: a surveillance, epidemiology, and end results database analysis. Cancer (2010) 116:3843-51. doi:10.1002/cncr.25149

16. Hoskin PJ, Kirkwood AA, Popova B, Smith P, Robinson M, Gallop-Evans E, et al. 4 Gy versus 24 Gy radiotherapy for patients with indolent lymphoma (FORT): a randomised phase 3 non-inferiority trial. Lancet Oncol (2014) 15:457-63. doi:10.1016/S1470-2045(14)70036-1

17. Li X, Abrahams C, Embry M, Yu A, Kahana J, Brown M, et al. Targeting CD74 with novel antibody drug conjugates (ADCs) for the treatment of B-cell non-Hodgkin's lymphoma (NHL). Blood (2016) 128:464.

18. Zammarchi F, Corbett S, Adams L, Mellinas-Gomez M, Tyrer P, Dissanayake S, et al. hLL2-Cys-PBD, a new site-specifically conjugated, pyrrolobenzodiazepine (PBD) dimer-based antibody drug conjugate (ADC) targeting CD22expressing B-cell malignancies. Blood (2016) 128:4176.

19. Ghielmini M, Schmitz S-FH, Cogliatti SB, Pichert G, Hummerjohann J, Waltzer U, et al. Prolonged treatment with rituximab in patients with follicular lymphoma significantly increases event-free survival and response duration compared with the standard weekly x 4 schedule. Blood (2004) 103:4416-23. doi:10.1182/blood-2003-10-3411

20. Hainsworth JD, Litchy S, Burris HA, Scullin DC, Corso SW, Yardley DA, et al. Rituximab as first-line and maintenance therapy for patients with indolent non-Hodgkin's lymphoma. J Clin Oncol (2002) 20:4261-7. doi:10.1200/ JCO.2002.08.674

21. McLaughlin P, Grillo-López AJ, Link BK, Levy R, Czuczman MS, Williams ME, et al. Rituximab chimeric anti-CD20 monoclonal antibody therapy for relapsed indolent lymphoma: half of patients respond to a four-dose treatment program. J Clin Oncol (1998) 16:2825-33. doi:10.1200/JCO.1998.16.8.2825

22. Liu SD, Chalouni C, Young JC, Junttila TT, Sliwkowski MX, Lowe JB. Afucosylated antibodies increase activation of Fc RIIIa-dependent signaling components to intensify processes promoting ADCC. Cancer Immunol Res (2015) 3:173-83. doi:10.1158/2326-6066.CIR-14-0125

23. Marcus R, Davies A, Ando K, Klapper W, Opat S, Owen C, et al. Obinutuzumab for the first-line treatment of follicular lymphoma. N Engl J Med (2017) 377:1331-44. doi:10.1056/NEJMoa1614598 
24. Kaminski MS, Tuck M, Estes J, Kolstad A, Ross CW, Zasadny K, et al. ${ }^{131}$ I-tositumomab therapy as initial treatment for follicular lymphoma. $N$ Engl J Med (2005) 352:441-9. doi:10.1056/NEJMoa041511

25. Ryan MC, Palanca-Wessels MC, Schimpf B, Gordon KA, Kostner H, Meyer B, et al. Therapeutic potential of SGN-CD19B, a PBD-based anti-CD19 drug conjugate, for treatment of B-cell malignancies. Blood (2017) 130:2018-26. doi:10.1182/blood-2017-04-779389

26. Martinelli G, Hsu Schmitz S-F, Utiger U, Cerny T, Hess U, Bassi S, et al. Longterm follow-up of patients with follicular lymphoma receiving single-agent rituximab at two different schedules in trial SAKK 35/98. J Clin Oncol (2010) 28:4480-4. doi:10.1200/JCO.2010.28.4786

27. Hamadani M, Horowitz MM. Allogeneic transplantation for follicular lymphoma: does one size fit all? J Oncol Pract (2017) 13:798-806. doi:10.1200/ JOP.2017.026336

28. Westin JR, Chu F, Zhang M, Fayad LE, Kwak LW, Fowler N, et al. Safety and activity of PD1 blockade by pidilizumab in combination with rituximab in patients with relapsed follicular lymphoma: a single group, open-label, phase 2 trial. Lancet Oncol (2014) 15:69-77. doi:10.1016/S1470-2045(13)70551-5

29. Lesokhin AM, Ansell SM, Armand P, Scott EC, Halwani A, Gutierrez M, et al. Nivolumab in patients with relapsed or refractory hematologic malignancy: preliminary results of a phase Ib study. J Clin Oncol (2016) 34:2698-704. doi:10.1200/JCO.2015.65.9789

30. Nastoupil LJ, Westin JR, Fowler NH, Fanale MA, Samaniego F, Oki Y, et al. Response rates with pembrolizumab in combination with rituximab in patients with relapsed follicular lymphoma: interim results of an on open-label, phase II study. J Clin Oncol (2017) 35:7519. doi:10.1200/JCO.2017.35.15_suppl.7519

31. Schuster SJ, Svoboda J, Nasta S, Porter DL, Mato A, Shah GD, et al. Phase IIa trial of chimeric antigen receptor modified T cells directed against CD19 (CTL019) in patients with relapsed or refractory CD19+ lymphomas. J Clin Oncol (2015) 33:8516. doi:10.1200/jco.2015.33.15_suppl.8516

Conflict of Interest Statement: The authors have had roles in advisory boards of Roche (FS and CR), BMS (FS), Celgene (CR), and Janssen (FS and CR).

Copyright (C) 2018 Stenner and Renner. This is an open-access article distributed under the terms of the Creative Commons Attribution License (CC BY). The use, distribution or reproduction in other forums is permitted, provided the original author(s) and the copyright owner are credited and that the original publication in this journal is cited, in accordance with accepted academic practice. No use, distribution or reproduction is permitted which does not comply with these terms. 